\title{
ÁRABE, FALE HEBRAICO: A LÍNGUA COMO ÚLTIMO REDUTO DA BATALHA IDENTITÁRIA DO ÁRABE ISRAELENSE
}

\section{ARAB, SPEAK HEBREW: THE LANGUAGE AS THE LAST REDOUBT OF \\ THE ARAB-ISRAELI'S IDENTITY BATTLE}

Juliana Portenoy Schlesinger*

\section{Resumo}

A língua é um componente importante quando abordamos a questão da identidade. No caso das crônicas do escritor árabe israelense Sayed Kashua, a temática da língua de escrita aparece quase que de maneira obsessiva. A maneira como Kashua trata o tema da língua não é convencional e nem poderia ser. Sayed Kashua é um árabe israelense que escreve toda a sua obra ficcional e jornalística em hebraico. Baseando-se na análise de diversas crônicas do autor publicadas no jornal israelense Haaretz, este artigo analisa como Kashua lida com a língua como uma ferramenta de identidade. Por meio do humor e da autoironia, este árabe israelense transita entre culturas, fidelidades e infidelidades e coloca a língua, tanto o hebraico quanto o árabe, no centro da batalha identitária e último reduto do árabe em contato com o ethos judaico israelense.

Palavras-chave: Sayed Kashua; língua; sociedade israelense; árabes israelenses; jornal Haaretz; crônicas jornalísticas.

\begin{abstract}
Language is a component that speaks loudly when we consider the issue of identity. As related to the chronicles of the Israeli Arab writer Sayed Kashua, this subject appears almost obsessively in his work, as a main or peripheral subject. The way Kashua addresses the issue of language is not conventional and could not be different since he writes all his fictional and journalistic work in Hebrew. Based on the analysis of several chronicles published in the Israeli newspaper Haaretz, this paper analyses how the chronicler deals with the issue of language as an identity tool. In his chronicles, always provided with humor and self-irony, the

\footnotetext{
* Juliana Portenoy Schlesinger é pesquisadora de pós-doutorado da USP com apoio da Fapesp, doutora em Língua e Literatura Hebraica pela USP, mestre em antropologia pela Universidade Hebraica de Jerusalém e bacharel em jornalismo pela PUC-SP e Ciências Sociais pela USP. E-mail: <juportenoy @ gmail.com>
} 
Israeli Arab transits between cultures, fidelities and infidelities, and puts languages, both Hebrew and Arabic, in the centre of the identity battle and the last stronghold in the contact with the Jewish Israeli ethos.

Key-words: Sayed Kashua; language; Israeli society; Israeli Arabs; Haaretz newspaper; chronicles. 
A língua é um componente que fala alto quando abordamos a questão da identidade. No caso das crônicas do escritor árabe israelense Sayed Kashua, a temática da língua aparece quase que de maneira obsessiva. Tão central é o tema para o cronista que, numa crônica, por exemplo, em que o eu-cronista ${ }^{2}$ confessa para sua esposa não saber sobre o que escrever naquela semana, ela responde: "Escreva sobre língua. Você adora o tema"3.

A maneira como Kashua trata o tema da língua não é convencional e nem poderia ser. Sayed Kashua é um árabe israelense que escreve toda a sua obra ficcional e jornalística em hebraico. Em Israel, as línguas são símbolos importantes de lealdades dos povos que lá vivem e o tema é controverso antes mesmo do país ser estabelecido. A discussão acerca de qual língua deveria ser falada no Estado judeu que seria um dia criado já aparece nas confabulações dos teóricos do Sionismo. Theodor Herzl, por exemplo, idealizador do Sionismo Político, doutrina que pregava o estabelecimento de um estado nacional judaico, acreditava que aquele país deveria ser multilíngue. Assim ele afirma no final do século XIX: "Nosso desejo por uma língua comum (no Estado judeu) apresenta dificuldades. Nós não podemos conversar uns com os outros em hebraico. Quem entre nós sabe hebraico suficientemente para comprar um bilhete de trem naquela língua? Isto não pode ser feito. Mas esta dificuldade pode facilmente ser superada. Cada homem pode preservar a língua na qual se sente em casa",

Naquela mesma época, o nacionalismo judaico não territorial, que pregava a permanência dos judeus nos seus países de origem, escolhera o iídiche como sua língua e, após as imigrações a então Palestina e depois da tragédia do Holocausto, perdeu em ambos os caminhos. O movimento territorialista sionista, por sua parte, objetivou criar o "Novo homem hebreu" e entre seus lemas estava "Hebreu: fale hebraico". Foi desta forma que a revitalização do hebraico como o maior componente da ideologia sionista e do nacionalismo judaico garantiu a esta língua um status ideologicamente privilegiado.

\footnotetext{
${ }^{2}$ Simon (2011) acredita que os termos "personagem" e "narrador" não são sempre adequados para classificar os personagens em determinadas crônicas. Para ele, “(...) em certas crônicas, a primeira pessoa do discurso nem sempre pode ser vinculada à pessoa física do cronista ou do escritor, porque, muitas vezes o eu se abstém de narrar optando apenas por comentar ou expor sentimentos” (p. 29). Segundo Simon (idem), “(...) este eu é uma criatura do cronista, criação que se desvincula de qualquer compromisso verídico ou autobiográfico, pois se inscreve em um modelo de texto que flerta também com situações científicas" (p. 53). Simon (idem) propõe a terminologia "eu do cronista" para desatrelar o autor das crônicas daquelas situações e emoções expostas por ele nos textos. Neste artigo, será utilizada a terminologia eu-cronista com o mesmo sentido atribuído pelo autor.

${ }^{3}$ Sayed Kashua motse pitron: nimtsá hapitron hamushlam lemachsom haktiva - diunim im anshei academia bechirim (Sayed Kashua encontra a solução: foi encontrada a solução perfeita para a falta de ideia - conversas com famosos professores). Haaretz. 21 de setembro de 2012. http://www.haaretz.co.il/magazine/sayed/1.1824247. Último acesso em 3 de dezembro de 2013.

${ }^{4}$ Tradução da autora.
} 
No momento da criação do Estado de Israel, o hebraico já era a língua principal da população judaica local e a alta heterogeneidade linguística da população que para lá imigrou contribuiu para a rápida aceitação do hebraico, o que incluiu os falantes do árabe, que rapidamente aprenderam o hebraico devido à proximidade das línguas.

O hebraico, na empreitada sionista, deixou de ser apenas um idioma religioso ${ }^{5}$ e foi transformado numa ferramenta diária em Israel. Constitui-se de tal maneira como bastião do Estado judeu que a identidade do judeu, em Israel ou na diáspora, tornou-se intrinsecamente ligada àquela língua.

Em Israel, o árabe e o hebraico são línguas oficiais ${ }^{6}$, mas o hebraico ganhou status privilegiado também entre os cidadãos árabes israelenses, que o tem como segunda língua. Dentre esta população, que hoje constitui uma minoria significativa em seus $20 \%$, o bilinguismo hebraico-árabe pende para o ao hebraico, principalmente entre a população árabe jovem, embora o árabe seja a maior fonte de identidade e de marco cultural do palestino ${ }^{7}$ e do árabe israelense, tal qual o hebraico o é para judeu. Os melhores empregos estão no setor judaico do país, bem como as melhores escolas e universidades.

Há muitas décadas os sociolinguistas apontam a língua como reduto cultural de um grupo étnico. Simbolicamente, a língua é este reduto e a batalha linguística, longamente traçada entre judeus e entre judeus e árabes, continua relevante para os árabes israelenses na voz aqui exposta e analisada do cronista Sayed Kashua.

Mas não seria um contrassenso um escritor árabe israelense que escreve em hebraico preocupar-se com a capacidade de seus filhos falarem a língua árabe? Pois é na interação paifilho/filha que o tema da língua ganha destaque nas crônicas jornalísticas de Sayed Kashua. Se fosse natural que os filhos de um casal de árabes falassem árabe - afinal, esta é a sua língua mãe -, nestes textos de Kashua isto não acontece. Algo maior e mais forte que a influência linguística e cultural dos pais toma conta dos filhos e este fato enfurece o eucronista. Mas nas crônicas de Kashua, a fúria vem acompanhada de muito humor e ironia, tornando-a mais simpática e digestiva.

\footnotetext{
${ }^{5} \mathrm{O}$ hebraico é considerado língua sagrada na medida em que a bíblia hebraica e o Talmude foram nela escritos, bem com a maior parte das rezas que constam nos livros de reza do povo judeu. Por este motivo, diversos grupos religiosos judaicos mantêm-na como língua restrita à esfera religiosa e o seu uso para necessidades do dia-a-dia é vetado. Com o sionismo, o hebraico ganhou conotação de língua laica.

${ }^{6}$ Recentemente, o congresso israelense debateu a possibilidade de o árabe deixar de ser uma língua oficial no país.

${ }^{7}$ Diferentemente dos árabes cidadãos israelenses, os palestinos são aqueles que foram expulsos ou fugiram de Israel na Guerra da Independência, assim como seus descendentes. Também os habitantes das terras ocupadas por Israel na Guerra de 1967 são conhecidos por palestinos.
} 
Assim conta a crônica ${ }^{8}$ :

Edith Piaf estava tocando no meu carro na manhã em que recebi a carta quando eu levava meu filho a sua escola bilíngue e minha filha a sua escola judaica ${ }^{9}$. Eles estavam brigando no assento traseiro do carro em hebraico e eu tive que ameaçá-los - em árabe. '(...) e lembre-me, filha, que precisamos encontrar para você um professor particular de árabe, OK? '(...) Mas pai, eu já tenho tanta lição de casa, e aula de música...' 'Língua é identidade', eu me ouvi sussurrando. 'Língua é pertencimento'. 'Então por que você...', ela começou. 'Não importa'. 'Por que eu o quê?' 'Por que você escreve em hebraico?' 10

Ora, se língua é pertencimento, é identidade, por que o árabe israelense, mesmo aquele que escreve em hebraico, que matricula seus filhos em escolas bilíngues ou judaicas, gostaria que seus filhos falassem árabe? A língua falada entre os filhos denota sua participação na sociedade israelense na qual o hebraico é a língua mais comum também entre os árabes inseridos na sociedade israelense.

Tão natural é falar em hebraico quanto corriqueiro é para o israelense fazer compras no Duty Free, tal qual relata a crônica que conta que o eu-cronista, ao participar de um festival internacional de literatura em Berlim, vê-se julgando em pensamento o autor tunisiano Abdelwahab Meddeb: “(Sua crítica) Seria uma coisa se ele vivesse no seu país, e não em Paris, ou se escrevesse em árabe e não em francês (...) quando recebi um SMS da minha esposa em hebraico: 'Você comprou no Duty Free aquilo que havia lhe pedido?',11.

Muito sobre o conflito entre o árabe e o hebraico, a dupla fidelidade de escritores que não escreveram em sua língua mãe ${ }^{12}$, a conotação dada ao uso do hebraico por árabes em Israel e o uso daquela língua por judeus falantes do árabe ${ }^{13}$, a existência de escolas bilíngue

\footnotetext{
${ }^{8}$ Aravi, daber ivrit: Sayed Kashua mechapes zehut (Árabe, fale hebraico: Sayed Kashua procura identidade). Haaretz. 5 de setembro de 2012. http://www.haaretz.co.il/magazine/sayed/1.1817934. Último acesso em 3 de dezembro de 2013.

${ }^{9}$ Em Israel, as escolas públicas são setorizadas por língua de instrução. Há o setor árabe, onde leciona-se em árabe e o judaico, onde a língua de ensino é o hebraico. As escolas bilíngues árabe-hebraico são escolas mistas, de capital público e privado.

${ }^{10}$ Toda tradução de crônica de Sayed Kashua do hebraico para o português é feita por esta autora e é de sua responsabilidade.

${ }^{11}$ Aviv aravi beBerlin: Sayed Kashua al asson 11.9 (Primavera árabe em Berlin: Sayed Kashua no horror de 11.9). Haaretz. 14 de setembro de 2013. http://www.haaretz.co.il/magazine/sayed/1.1823218. Último acesso em 3 de dezembro de 2013.

12 SCHLESINGER, Juliana P. O árabe e o hebraico como agentes definidores de identidade na sociedade israelense: o caso de Sayed Kashua. Cadernos de literatura hebraica, no. 6., Targumim, São Paulo 2008 , p. 175-190.

${ }^{13}$ SCHLESINGER, Juliana P. Conflitos identitários do árabe israelense: Aravim Rokdim de Sayed Kashua (Tese de Doutorado). Programa de Pós-Graduação em Língua Hebraica, Literatura e Cultura Judaicas e Língua, Literatura e Cultura Árabe, Departamento de Letras Orientais da Faculdade de Filosofia, Letras e Ciências Humanas, Universidade de São Paulo, 2011.
} 
árabe-hebraico em Israel ${ }^{14}$ já foi escrito. Esta autora, em especial, dedica-se há anos ao tema. Neste artigo, a intenção é verificarmos e analisarmos a maneira como o cronista Sayed Kashua expõe este tema para ele tão sensível.

Selecionado como um dos autores dos livros finalistas de um prêmio na França, o cronista nos conta numa crônica ${ }^{15}$ que seu editor francês pediu que respondesse a algumas questões: "O que a língua significa para você?" e "O que significa ser um árabe no Estado judeu?". Do mesmo modo, numa outra crônica ${ }^{16}$ o cronista menciona que numa conferência sobre seu trabalho, as seguintes perguntas lhe foram direcionadas: "Por que você escreve em hebraico?", "Em que língua você sonha?" e "Como seu trabalho é recebido na comunidade árabe?".

O cronista confessa ser frequentemente questionado a respeito do uso que faz da língua hebraica. Aliás, a maior fonte de crítica negativa ao seu trabalho advêm deste fato - tanto a provinda de judeus quanto de árabes. As perguntas acima relatadas nas crônicas conectam o tema sem delongas: língua e identidade caminham juntas, especialmente em locais de conflito étnico, como no caso de Israel.

À proposta feita naquela primeira crônica aqui exposta, na qual a esposa do eu-cronista sugere que ele, na falta de criatividade, fale sobre língua, ele aceita. ${ }^{17}$

Estamos tentando ensinar o bebê a falar já faz algum tempo. Nada, nem uma palavra. Ele não responde. Nesta idade, ele já poderia pronunciar algumas palavras (...). Há meses tentamos ensiná-lo a dizer 'luz' em árabe (dor) ao apontar para o lustre, e assim por diante (...). Então, nesta semana, minha esposa acendeu a luz e ele disse luz em hebraico (or). Com a pronúncia judaica da letra resh $^{18}$ e tudo o mais. Já fazia tempo que sabíamos que o bebê, que frequenta uma pré-escola no nosso bairro (de maioria judaica) falava algumas palavras em hebraico: oto (carro), aba (pai), delet (porta). 'É por causa da escolinha', minha esposa disse. 'Eu estava tão preocupada e de repente descobrimos que ele fala hebraico'.

14 SCHLESINGER, Juliana P. Languages reveal boundaries of identity in a Bilingual Arabic-Hebrew Kindergarten in Jerusalem. LAP Lambert Academic Publishing, Saarbrücken, Alemanha, 2011.

${ }_{15}$ Aravi, daber ivrit: Sayed Kashua mechapes zehut (Árabe, fale hebraico: Sayed Kashua procura identidade). Haaretz. 5 de setembro de 2012. http://www.haaretz.co.il/magazine/sayed/1.1817934. Último acesso em $3 \mathrm{de}$ dezembro de 2013.

${ }^{16} \mathrm{Mi}$ ze haish hazaken haze shemabit bi bamarhe. (Quem é este homem velho que eu vejo no espelho). Haaretz. 17 de janeiro de 2012. http://www.haaretz.co.il/magazine/sayed/1.1909583. Último acesso em 3 de dezembro de 2013.

${ }^{17}$ Sayed Kashua motse pitron: nimtsá hapitron hamushlam lemachsom haktiva - diunim im anshei academia bechirim (Sayed Kashua encontra a solução: foi encontrada a solução perfeita para a falta de ideia - conversas com famosos professores). Haaretz. 21 de setembro de 2012. http://www.haaretz.co.il/magazine/sayed/1.1824247. Último acesso em 3 de dezembro de 2013.

18 Árabes e judeus pronunciam certas letras do alfabeto hebraico de maneira diferente, principalmente no que se refere às letras guturais. Exceção acontece entre os judeus provindos dos países árabes, mas que nesta crônica não recebem atenção especial. 
E assim, o casal diz-se aliviado, afinal, o nenê pode falar - mesmo que em hebraico. Mas o autor faz chacota. Ele não consegue abster-se de fazer piada do assunto. Assim prossegue a crônica: "Agora, tudo o que precisamos é fazê-lo dormir a noite toda. Seu choro está me enlouquecendo (diz a esposa)' 'Mas como ele conseguiria dormir? Este bebê hebraico sabe que há dois árabes ${ }^{19}$ junto a ele num quarto escuro"”.

A ideia de que a língua que você fala determina a sua identidade é antiga nas ciências sociais e no contexto israelense, denota que o árabe que fala hebraico está inserido na sociedade israelense judaica, enquanto que, neste contexto, aquele árabe que não fala hebraico, que só vive entre árabes, é um árabe que não se assimilou àquela sociedade e por isso pode ser perigoso. Ele é, de antemão, suspeito.

Mas os filhos do eu-cronista estão plenamente adaptados à sociedade israelense hebraica. Eles brigam em hebraico, não têm tempo para estudar o árabe. A própria avó, numa outra crônica, confessa uma preocupação a esta "super-integração"

Minha mãe (do eu-cronista) estava tão feliz com a ideia de ter uma antena parabólica árabe, mas não pelo o fato de ter acesso à $\mathrm{Al} \mathrm{Jazeera.} \mathrm{'Ao} \mathrm{menos}$ as crianças poderão assistir desenhos em árabe literário', ela disse. 'Eles ouvem hebraico o dia inteiro. Você verá, com este satélite, o árabe deles melhorará'.

Aqui, a Al Jazeera faria o contato daquela população árabe israelense com o mundo árabe, mas isto é irrelevante. Ela quer que seus netos israelenses falem árabe.

Em diversas crônicas, o eu-cronista esconde sua identidade árabe intencionalmente ao falar hebraico ${ }^{21}$ ou em muitos casos, finge não saber árabe para ouvir o que os árabes a sua volta estão dizendo ${ }^{22}$. Assim, o uso das línguas é explicitamente instrumentalmente orientado. Transitar entre culturas, entre identidades, entre lealdades e infidelidades é coisa que a escolha de qual língua usar permite.

Numa outra crônica, o eu-cronista, ao contratar um eletricista árabe para consertar um problema no seu quadro de luz, sente-se embaraçado pelo fato de seus filhos falarem hebraico diante daquele senhor ${ }^{23}$.

\footnotetext{
${ }^{19}$ Em referência aos outros dois filhos do cronista.

Meabdim shlita (Perda de controle). Haaretz. 22 de agosto de 2013. http://www.haaretz.co.il/magazine/sayed/.premium-1.2103920. Último acesso em 3 de dezembro de 2013.

${ }^{21}$ Chotvei etsim veshoavei avak (Cortadores de árvores e aspiradores de pó). Haaretz. 27 de junho de 2013. http://www.haaretz.co.il/magazine/sayed/.premium-1.2057208. Último acesso em 3 de dezembro de 2013.

$22 \mathrm{Al}$ vikuach al chanaiá vedeot kodmot (Sobre a briga pela vaga no estacionamento e preconceitos). Haaretz. 18 de outubro de 2013. http://www.haaretz.co.il/magazine/sayed/.premium-1.2143158. Último acesso em 3 de dezembro de 2013.

23 Chashmal baavir (Queda de energia). Haaretz. 23 de maio de 2013. http://www.haaretz.co.il/magazine/sayed/.premium-1.2028185. Último acesso em 3 de dezembro de 2013.
} 
'O problema foi com a ponte (de eletricidade)'. 'Ponte?', eu perguntei. Eu nunca ouvira falar em ponte de eletricidade. 'É complicado?'. '(...) Não será complicado trazer energia de novo mas todos os fusíveis devem ser trocados'. 'Café?'. 'Claro, obrigado'. 'Com leite?'. 'Você não tem café árabe?'. 'Não', respondi envergonhado. 'Então qualquer coisa serve', disse o eletricista em tom de condolência. Eu fiz café. A voz das crianças vinda do quarto poderia ser ouvida. Eles falavam em hebraico. Eu pedi que baixassem a voz. 'E se possível', sussurrei, 'falem em árabe, ok?'. 'Obrigado', disse o eletricista (...), 'mas desculpe a pergunta, você é árabe, não?'. 'Sim', eu respondi, 'claro'. 'Desculpe te dizer', disse entre goles, 'mas uma árvore sem raízes fortes não dará frutos'. 'Pode ser', eu respondi envergonhado na medida em as crianças voltaram a falar hebraico. 'Não fique bravo por eu te falar isso', ele disse, 'mas eu não gosto de pessoas que imitam outras'. 'Claro', eu disse gaguejando, 'nem eu'. 'Veja seus filhos. Lo haram? Não é uma pena?', quando meu filho veio até a sala e perguntou em árabe se já poderia assistir televisão. Eu não sei o que aconteceu, mas me vi me desculpando e me sentindo envergonhado e acossado pelo eletricista que veio de Jerusalém Oriental ${ }^{24}$ consertar um fusível. Meu olhar estava baixo e eu balançava minha cabeça ao concordar com tudo o que ele dizia, sentindome um menininho sendo reprimido pelos pais depois de fazer algo feio. ' $O$ que é uma pessoa sem história, sem raízes, longe de sua condição natural? Nada, certo?'. 'Sim'.

O eletricista sugere que, no caso do eu-cronista permanecer naquela casa, que comprasse um novo fusível, mas ele recomendou que eles se mudassem "para um lugar onde pudessem criar seus filhos".

'Você sabe que dia é hoje?', meu filho perguntou, pegando o eletricista, e especialmente eu, de surpresa. 'Quarta-feira?', ele respondeu sorrindo'. '(...) Eu sei que é quarta-feira, mas que dia especial é hoje?'. 'Shavuot?', ele disse direcionando-me um sorriso. 'Não', disse meu filho. 'Shavuot é um feriado judaico - ontem comemos queijo e quiches com nossos vizinhos. Que dia é hoje para os árabes?'. O eletricista não tinha a menor ideia. 'Hoje é o Dia da $N a k b a^{25}$, eu disse, ajudando o eletricista. 'É mesmo? Uma pessoa trabalha tanto que...'. 'Você sabe o que o Dia da Nakba significa?', ele disse num tom tão áspero que eu tive que reprimi-lo com o olhar.

Nesta crônica, ocorre um debate entre árabes a respeito do que significa ser um árabe em Israel. De que maneira seguir fiel à narrativa árabe do conflito árabe-israelense, de que

\footnotetext{
${ }^{24}$ Jerusalém esteve em posse da Jordânia até a Guerra do Iom Kipur, em 1967, quando Israel conquistou-a. A população árabe de Jerusalém Oriental, maioria na região, não tem cidadania israelense e sim possui um status especial, diferentemente do que ocorreu com a população árabe que vivia em território conquistado por Israel na Guerra da Independência, em 1948. Até hoje, o status de Jerusalém Oriental está em aberto. Israel declara Jerusalém sua capital eterna e indivisível, enquanto que muitos árabes almejam que um futuro Estado palestino, criado ao lado de Israel, tenha como sua capital Jerusalém Oriental. De qualquer modo, a população árabe de Jerusalém Oriental, segundo pesquisas e artigos, comporta-se de maneira diferente quando comparada à população árabe israelense, por exemplo no que se refere ao voto. Esta população costuma boicotar as eleições para a prefeitura da cidade e vive numa região quase que predominantemente árabe, em oposição ao eu-cronista desta crônica, que afirma viver entre judeus.

${ }^{25}$ A narrativa tradicional palestina vê o Dia da Independência de Israel e sua vitória sobre os estados árabes como uma catástrofe, e assim a data é conhecida em árabe como Al Nakba, o Dia da Destruição em árabe.
} 
maneira ser fiel às suas raízes e ao futuro comum de seu povo? É por meio da língua? É o café que se toma? É o local onde o árabe vive que denota seu pertencimento à sua comunidade de origem e seus valores quanto povo? Sua fidelidade está em conflito com seus valores quando sua língua é trocada pela língua da maioria? Estes são questionamentos que o próprio eucronista vem se fazendo em todas estas crônicas. A ponte de eletricidade seria, metaforicamente, esta ponte cultural que permite ao árabe morar entre judeus e comemorar Shavuot junto aos seus vizinhos e ainda lembrar-se da Nakba?

Numa outra crônica ${ }^{26}$, Sayed Kashua nos conta que, numa entrevista, o público dirigiu a ele algumas perguntas: "Como você ousa usar a língua hebraica?', perguntou-me uma palestina refugiada ${ }^{27}$ que nascera em Jafa. “A língua na qual o seu povo é oprimido". Na mesma ocasião, outra pessoa opinou: "Você deveria ser agradecido por viver num país onde tem liberdade de escrever. Sobre o que você escreveria se tivesse nascido na Síria?”.

São dois lados da mesma moeda. Por um lado, morar um país onde é possível escolher a língua de trabalho, no caso do autor, onde seus filhos podem transitar entre idiomas sem no entanto abrir mão de sua identidade, mas ao mesmo tempo ser sim um traidor de uma língua que representa, para muitos, a sua luta como povo nacional. Abrir mão desta língua, e detrimento da língua da maioria, seria sim uma traição. O título dado à crônica, Sayed Kashua quer que os dois lados vão para o inferno, é o desejo de ser livre e não precisar prestar contas para ninguém: nem para aquele que passam a mão na sua cabeça, defendendo suas escolhas, nem para aqueles que condenam suas escolhas. Mas na realidade, as duas vozes são ouvidas e fazem sentido ao eu-cronista. Ele sente-se envergonhado frente ao eletricista por seus filhos falarem hebraico; ele gostaria que seus filhos falassem árabe, mas eles estudam em escolas bilíngue ou judaica.

Numa outra crônica ${ }^{28}$, o cronista afirma que ele precisa "urgentemente de um acordo de paz para justificar a língua que uso".

Toda vez que busco meu filho pequeno na escola, eu percebo o quanto pessoalmente preciso deste acordo. Não basta o fato de ele não saber uma única palavra em árabe, ele também me chama de 'Said', como um verdadeiro ashkenazita $^{29}$. É verdade, hebraico é a língua que ele ouve em sua escolinha, mas em casa eu me policio para responder suas perguntas em árabe. Mas ele insiste que não entende nem uma palavra nesta língua

26 Beit mishpat! (Corte de justiça). Haaretz. 23 de março de 2013. http://www.haaretz.co.il/magazine/sayed/.premium-1.1973067. Último acesso em 3 de dezembro de 2013.

${ }^{27}$ Vide nota número 5

28 Ani, haezrach $(E u, \quad o \quad$ cidadão $)$ Haaretz. 25 de julho de 2013. http://www.haaretz.co.il/magazine/sayed?hideOthers=7.2650886\&page=1\&listId=7.2650886\&hideOthersInSlot $=$ main\#listAnchor7.2650886. Último acesso em 3 de dezembro de 2013 .

${ }^{29}$ Vide nota número 16. 
estranha que seu pai usa. Quando vamos a Tira, meus pais ficam possessos quando ouvem o bebê falando em hebraico. Nada enfurece meu pai mais do que ouvir seu neto chamando-o de 'saba', o que me faz rir. Mas eu não simpatizo muito com o apelido que ele lhe deu: Pequeno Sião ${ }^{30}$.

Neste trecho de crônica acima relatado, sintetiza-se o que aqui está sendo dito. O árabe, quando inserido na sociedade judaico-israelense, precisa fazer um esforço para ensinar aos seus filhos a língua árabe. Ele precisa se policiar para manter esta língua viva entre a nova geração de árabes israelenses, que frequentam escolas (no caso pré-escola) judaicas, enquanto que a primeira geração de árabes israelenses, aquela que viu o estabelecimento do Estado de Israel e aqui representada pelo pai do eu-cronista, tal qual sua mãe na crônica da antena parabólica e o árabe eletricista, a língua árabe continua sendo a sua grande fonte de identidade. Para esta segunda geração, representada pelo eu-cronista, o árabe continua tendo importância na sua definição identitária, mas menos importante quando comparada à importância dada pela geração que o antecede. Na terceira geração, representada pelos filhos do eu-cronista, ao menos enquanto crianças ou jovens, como no caso da filha, que aparece na crônica em que ela diz não ter tempo para estudar o árabe, pois na sua lista de prioridades estão outros itens, como aula de música, o árabe já não é mais a maior fonte de sua identidade. O garoto, no caso da crônica do eletricista, deixa isto explícito: é possível ser um árabe em Israel que recorda da Nakba falando o hebraico. Para esta geração, é possível ser árabe em Israel, com todo o peso identitário que isto significa, sem passar pela língua. É uma grande mudança que ocorreu de modo geracional. De fato, a questão referente a prioridades, identificações e fidelidades de cada uma das gerações de árabes israelenses é tema que aparece, de maneira central ou periférica, frequentemente nas crônicas de Sayed Kashua.

O eu-cronista, pai do "Pequeno Sião", acredita que a paz solucionaria seu problema, digamos, étnico-linguístico. O uso que ele e seus filhos fazem da língua hebraica perderia sua conotação política - o quão traidor da causa árabe será o árabe que fala o hebraico em detrimento da língua árabe quando árabes e judeus deixarem de ter problemas entre si e vivessem em paz? O eu-cronista acredita que ele não mais será um traidor e nem mais um imitador do judeu. Esta será sua nova identidade. Não é por acaso que a crônica em que a filha do eu-cronista o questiona por que ele escreve em hebraico se o árabe para ele é tão importante recebeu o título “Árabe: fale hebraico". Para este cronista, no momento em que o árabe puder ser um novo homem (hebraico), a paz terá sido alcançada e ele poderá, por fim, entregar-se à língua hebraica sem necessariamente abrir mão de sua identidade enquanto árabe israelense.

\footnotetext{
${ }^{30}$ Sião é a maneira como Jerusalém, a Terra Prometida por Deus aos judeus, é designada na Bíblia Hebraica.
} 
Retomando a crônica Corte de Justiça ${ }^{31}$,

Está tudo bem, pensei comigo mesmo (...) ao lembrar as críticas de judeus e de árabes (...). Está tudo bem. Nós estamos bem. Eu posso estar confuso. Podemos ser inconsistentes quando falamos sobre identidade, sobre língua e nacionalidade. Está tudo bem (...). De alguma forma, eu sussurrei para mim mesmo (...), de alguma maneira estaremos bem no final.

Ser inconsistente talvez seja uma característica típica da geração deste eu-cronista. Ele já não carrega mais o peso histórico da primeira geração de árabes israelenses, entre a qual a língua é uma bandeira que deve ser hasteada no contato com o judeu. Mas ele não tem a liberdade da terceira geração de árabes israelenses, entre os quais é possível falar o hebraico sem grandes consequências ideológicas. Ele está no meio do caminho. É uma inconsistência que talvez seja intrínseca à sua condição. Mas é esta inconsistência o motor propulsor para tão interessante ponto de vista.

Parafraseando Herzl, não só o hebraico atingiu o status de língua franca quanto o árabe passou a se sentir em casa em Israel, mesmo que esta casa precise de uma antena parabólica que pegue a Al Jazeera. 


\section{Referências}

HERZL, Theodor. O Estado judeu. Dover edition, New York, 1988.

KASHUA, Sayed. Mi ze haish hazaken haze shemabit bi bamarhe. (Quem é este homem velho que eu vejo no espelho). Haaretz. 17 de janeiro de 2012. http://www.haaretz.co.il/magazine/sayed/1.1909583. Último acesso em 3 de dezembro de 2013.

KASHUA, Sayed. Aravi, daber ivrit: Sayed Kashua mechapes zehut (Árabe, fale hebraico: Sayed Kashua procura identidade). Haaretz. 5 de setembro de 2012. http://www.haaretz.co.il/magazine/sayed/1.1817934. Último acesso em 3 de dezembro de 2013.

KASHUA, Sayed. Sayed Kashua motse pitron: nimtsá hapitron hamushlam lemachsom haktiva - diunim im anshei academia bechirim (Sayed Kashua encontra a solução: foi encontrada a solução perfeita para a falta de ideia - conversas com famosos $\begin{array}{lllll}\text { professores). } & \text { Haaretz. } & 21 & \text { de }\end{array}$ http://www.haaretz.co.il/magazine/sayed/1.1824247. Último acesso em 3 de dezembro de 2013.

KASHUA, Sayed. Beit mishpat! (Corte de justiça). Haaretz. 23 de março de 2013. http://www.haaretz.co.il/magazine/sayed/.premium-1.1973067. Último acesso em 3 de dezembro de 2013.

KASHUA, Sayed. Chashmal baavir (Queda de energia). Haaretz. 23 de maio de 2013. http://www.haaretz.co.il/magazine/sayed/.premium-1.2028185. Último acesso em 3 de dezembro de 2013.

KASHUA, Sayed. Chotvei etsim veshoavei avak (Cortadores de árvores e aspiradores de pó). Haaretz. 27 de junho de 2013. http://www.haaretz.co.il/magazine/sayed/.premium1.2057208. Último acesso em 3 de dezembro de 2013.

KASHUA, Sayed. Ani, haezrach (Eu, o cidadão). Haaretz. 25 de julho de 2013. http://www.haaretz.co.il/magazine/sayed?hideOthers=7.2650886\&page=1\&listId=7.265 0886\&hideOthersInSlot=main\#listAnchor7.2650886. Último acesso em 3 de dezembro de 2013.

KASHUA, Sayed. Meabdim shlita (Perda de controle). Haaretz. 22 de agosto de 2013. http://www.haaretz.co.il/magazine/sayed/.premium-1.2103920. Último acesso em 3 de dezembro de 2013. 
KASHUA, Sayed. Aviv aravi beBerlin: Sayed Kashua al asson 11.9 (Primavera árabe em Berlin: Sayed Kashua no horror de 11.9). Haaretz. 14 de setembro de 2013. http://www.haaretz.co.il/magazine/sayed/1.1823218. Último acesso em 3 de dezembro de 2013.

KASHUA, Sayed. Al vikuach al chanaiá vedeot kodmot (Sobre a briga pela vaga no estacionamento e preconceitos). Haaretz. 18 de outubro de 2013. http://www.haaretz.co.il/magazine/sayed/.premium-1.2143158. Último acesso em 3 de dezembro de 2013.

SCHLESINGER, Juliana P. O árabe e o hebraico como agentes definidores de identidade na sociedade israelense: o caso de Sayed Kashua. Cadernos de literatura hebraica, no. 6., Targumim, São Paulo 2008, p. 175-190.

SCHLESINGER, Juliana P. Conflitos identitários do árabe israelense: Aravim Rokdim de Sayed Kashua (Tese de Doutorado). Programa de Pós-Graduação em Língua Hebraica, Literatura e Cultura Judaicas e Língua, Literatura e Cultura Árabe, Departamento de Letras Orientais da Faculdade de Filosofia, Letras e Ciências Humanas, Universidade de São Paulo, 2011.

SCHLESINGER, Juliana P. Languages reveal boundaries of identity in a Bilingual Arabic-Hebrew Kindergarten in Jerusalem, Saarbrücken, Alemanha: LAP Lambert Academic Publishing, 2011.

SIMON, Luiz Carlos. Duas ou três páginas despretensiosas - a crônica, Rubem Braga e outros Cronistas. Londrina: Eduel, 2011. 